\title{
A Escola de Formação em Saúde da Família Visconde Sabóia: narrativas que resgatam uma história
}

\author{
The Training School in Family Health \\ Care Visconde Sabóia: narratives that recover a story
}

Maria José Galdino Saraiva¹, Eliany Nazaré Oliveira², Maria Socorro de Araújo Dias,2, Lielma Carla Chagas da Silva ${ }^{1,3}$, Cleide Carneiro ${ }^{4}$

${ }^{1}$ Escola de Formação em Saúde da Família Visconde de Sabóia (EFSFVS) - Sobral (CE), Brasil.

${ }^{2}$ Centro de Ciências da Saúde, Enfermagem da Universidade Estadual Vale do Acaraú (UVA) - Crateús (CE), Brasil.

${ }^{3}$ Universidade Federal do Ceará (UFC) - Fortaleza (CE), Brasil.

${ }^{4}$ Universidade Estadual do Ceará (UECE) - Fortaleza (CE), Brasil.

DOI: http://dx.doi.org/10.7322/abcshs.v40i3.795

\section{RESUMO}

Introdução: A institucionalização do Sistema Único de Saúde (SUS) trouxe inovações no campo da formação e gestão, promovendo melhoria na qualificação dos trabalhadores. Para atender a esta demanda foram instituídas as Escolas Técnicas do SUS que se propõem a realizar esta atividade em consonância com as necessidades das instituições de saúde e da Reforma Sanitária. Objetivo: Sabendo da importância dos centros formadores, objetivou-se descrever as narrativas presentes no cenário da Educação na Saúde acerca da Escola de Formação em Saúde da Família Visconde de Sabóia (EFSFVS). Métodos: O estudo utiliza abordagem qualitativa de caráter exploratório-descritivo favorecendo a exploração da gênese da EFSFVS. A análise do estudo compreendeu o período de 2001 a 2012, palmilhando a exploração da história oral e documentos, tendo como sujeitos dez memorialistas com seus relatos oral, através de entrevistas, complementados pela análise documental. Resultados: Identificou-se um fosso de registros sistematizados da História da Instituição possibilitando um possível esquecimento da memória carecendo de estudos que possam contribuir na uniformização e concentração das informações e a relação dialógica da EFSFVS com os segmentos que compõem o quadrilátero da Saúde. Outra evidência foi a existência de uma intensa relação entre a EFSFVS e o Controle Social, como: reuniões, participação em conferências e processos formativos tendo como público alvo os conselheiros. Conclusão: A EFSFVS teve sua criação e implantação a partir da necessidade de formação e educação permanente para os trabalhadores e desde então vem contribuindo na qualificação profissional, com algumas limitações referentes a documentações que possam relatar sua história.

Palavras-chave: educação em saúde; capacitação de recursos humanos em saúde; instituições acadêmicas; Sistema Único de Saúde.

\begin{abstract}
Introduction: The institutionalization of the Brazilian Unique Health System (SUS) brought innovations for the formation and administration's field, promoting a upgrade in worker's qualification. For attend this demand was instituted the SUS's Technics Schools, who have the purpose of making this activity following the necessities of the health's institutions and of the Sanitary Reform. Objective: Knowing the central position of the centers of formation, this study had proposed the description of narrations about the Formation School of Family's Health Visconde de Saboia (EFSFVS). Methods: This study uses the qualitative approach of explorative-descriptive features, exploring the beginning of EFSFVS. The studied period was located between the years of 2001-2012, exploring the oral history of ten individuals, method complemented by the documental analysis. Results: Was identified a gap in the institution's systematized records, opening the hypothesis of oblivion caused by the absence of studies what allow the standardization and concentration of information and about the relationship between the EFSFVS and the others characters of Health's Quadrilateral. Another evidence was the intense flow between the EFSFVS and the Instruments of Social Control. Conclusion: EFSFVS's beginning was motivated by the necessity of formation and permanent education for the workers and, since that, was contributing with the professional qualification, despite the cadence of physical records about her history.
\end{abstract}

Keywords: health education; health human resource training; schools; Unified Health System. 


\section{INTRODUÇÃO}

A I Conferência Nacional de Recursos Humanos (CNRHS), recomendada, paralelamente, pela VIII Conferência Nacional de Saúde (CNS), tematizou a "Política de Recursos Humanos rumo à Reforma Sanitária”, e equiparou-se ao ambiente de expectativas em torno da possibilidade de implantação de um Sistema Único de Saúde ${ }^{1}$. Do ponto de vista geral, tratava-se da modificação das políticas de saúde, em sua maioria arcaicas, herdadas do Regime Militar (1964-1985) e da elaboração de uma Constituição que reinstituísse o regime democrático no Brasil e promovesse uma amenização dos danos sociais provocados pelo Regime.

Apesar da institucionalização do Sistema Único de Saúde², o final da década de 1990 foi dificultoso para a área da Saúde, uma vez que, a partir de 1990, com a posse de Fernando Collor de Melo e o início de um incipiente processo Neoliberal, ocorreram políticas de desestatização, privatização e ajuste econômico, que visavam reduzir ao mínimo a interferência do Estado na Sociedade ${ }^{3}$.

No entanto, tais dificuldades não impediram a introdução de inovações no campo da formação e gestão do pessoal de saúde. Dentre estas, se destacam o Projeto de Capacitação em Desenvolvimento de Recursos Humano em Saúde (CADRHU), o curso de Gerência de Unidades de Saúde do SUS (GERUS), ambos voltados para a qualificação dos quadros técnico-gerenciais; e, para atender à demanda de qualificação de profissionais possuidores de nível fundamental e médio foi proposto o Projeto Larga Escala (PLE), que viabilizaria escolas e centros formadores do SUS, além de promover melhoria da formação profissional de trabalhadores de nível médio e fundamental da saúde ${ }^{1}$.

Estes Centros atualmente denominados de Escolas Técnicas do SUS (ETSUS) se propunham a realizar a qualificação profissional de forma descentralizada em consonância com as exigências das instituições de Saúde e da Reforma Sanitária. Sendo mantidas pelo Sistema de Saúde, para atender às necessidades do setor, essas têm identidade com o trabalho de formação dos profissionais de nível médio do SUS ${ }^{4}$.

As ETSUS desenham suas ações a partir das necessidades do serviço identificadas pelos gestores, como preconiza a Política Nacional de Educação Permanente em Saúde (PNEPS). Dessa forma, as Escolas são incentivadas a participar ativamente dos Colegiados de Gestão e das Comissões de Integração Ensino-Serviço.

Partindo do contexto sócio-histórico do estado brasileiro, no campo da saúde pública, o principal desafio era a missão de subsidiar as novas políticas decorrentes das profundas mudanças. Sobral, município localizado no estado do Ceará, que acompanhava tais mudanças, diante do estabelecimento de um novo projeto político-administrativo para a saúde, com a então implantação do Programa Saúde da Família (PSF) tendo como campo prioritário a Atenção Básica, vinha a exigir do seu escopo profissional uma atuação qualificada baseada nas reflexões e constatações de que sua prática deveria estar pautada na troca construtiva de reflexão-ação-reflexão.
É então instituída, em 2001, a Escola de Formação em Saúde da Família Visconde de Sabóia (EFSFVS), em Sobral, com uma atitude ousada e desafiadora, que se dispunha a fomentar e desenvolver processos educacionais que viabilizassem a qualificação dos profissionais de saúde da família, gerando, no exercício de sua prática, novas competências e posturas adequadas ao modelo de atenção proposto. Ao longo dos seus quatorze anos, a EFSFVS vem viabilizando de forma crescente e vertiginosa os processos educacionais na saúde para o profissionais do sistema de saúde.

Sabe-se da importância e necessidade do arquivamento das informações e documentos inseridos nos processos de formação como ferramenta para atualização, reflexão e modificação para melhoria dos processos educacionais.

No entanto, o acervo das informações da EFSFVS não se constitui um arquivamento consolidado e centralizado nas dependências da Instituição. Elas estão incorporadas na memória de profissionais, comunidade e gestores que a vivenciaram possibilitando uma fragmentação e um possível esquecimento da memória de sua história, carecendo de estudos que possam contribuir na uniformização e concentração das informações.

Diante do exposto, objetivou-se descrever as narrativas presentes no cenário da Educação na Saúde acerca da EFSFVS.

\section{MÉTODOS}

Defendemos a premissa de que toda pesquisa deve explicitar, no seu texto, a abordagem teórico-filosófica em que está ancorada, dando condições ao leitor de uma melhor compreensão do processo metodológico utilizado.

Para consecução do objetivo desta pesquisa, será essencial ampliar o modo de alcançar as informações em relação à interpretação dos discursos que alguns dos protagonistas da história da EFSFVS revelam, além de fontes documentais que desnudam a história da Instituição em apreço.

Para obtenção desse desígnio, optamos por palmilhar o percurso da história oral e análise documental, como estratégias metodológicas, mais especificamente a história oral temática, cuja abordagem encontrou eco nas intenções desta pesquisa, visto que é uma metodologia voltada à experiência vivencial daquele que narra, ou na busca de informações factuais ${ }^{5,6}$.

Para se assegurar a cientificidade da história oral, há duas metas que devem ser garantidas, quais sejam:

- o caráter de documento feito por relatos orais;

- as derivações naturais da transferência do estágio oral para o escrito $^{6}$.

O estudo utiliza abordagem qualitativa ${ }^{7}$ de caráter exploratório e descritivo que favorece a exploração da gênese da Escola de Formação em Saúde da Família Visconde de Sabóia e o desenvolvimento de suas ações e nos permitirá um arraigar na trajetória de pessoas que participaram da construção desta Instituição. 
Como cenário, este estudo analisa a história de uma Escola de Formação para o SUS, sediada em Sobral, vocacionada em promover processos educativos interprofissionais, dialógicos, participativos, social e culturalmente contextualizados, para a qualificação da gestão, do ensino, da atenção e da participação social no âmbito do SUS, fortalecendo o Sistema Saúde Escola. Tendo por meta seu reconhecimento até 2023, em âmbito local, regional, estadual e nacional como escola pública, cidadã, inovadora nos processos de educação na saúde e comprometida com o fortalecimento e qualificação do SUS, notabilizando-se pela valorização de seu corpo docente, técnico administrativo e de suas parcerias institucionais ${ }^{8}$.

O período analisado por este estudo compreendeu o intervalo de tempo entre a Institucionalização da EFSFVS (2001) até o ano letivo de 2012. Os sujeitos participantes da pesquisa foram: coordenador de departamento (1), coordenador geral (1), diretores (3), preceptor/tutor (1), egressos de cursos (2), técnico (1) e representante do controle social (1). Para manter sigilo optou-se por identificar os sujeitos por: Entrevistado 1 (E1), E2, ..., E10.

Para coleta de dados, utilizou-se da técnica de entrevista, realizada com os sujeitos do estudo, com o objetivo de resgatar a memória da instituição por meio da história oral, complementada pela pesquisa documental através da leitura e análise dos documentos identificados (cartas, memorandos e outros tipos de correspondências, agendas, avisos, minutas de reuniões, relatórios escritos de eventos em geral, documentos administrativos, relatórios de avaliação e outros).

Sabendo que toda pesquisa que se propõe a trabalhar com seres humanos apresenta implicações éticas que necessitam ser discutidas e adequadas para sua execução, para se cumprir as determinações éticas previstas, o estudo foi submetido a apreciação ética pelo Comitê de Ética e Pesquisa da Universidade Estadual Vale do Acaraú - (UVA), obtendo parecer favorável com protocolo de CAAE $n^{\circ}$ 178192.13.8.0000.5053, observando rigorosamente as recomendações contidas na Resolução n $466 / 12^{9}$.

\section{RESULTADOS E DISCUSSÃO}

Na possibilidade, tencionamos a consolidar as informações obtidas a partir das entrevistas com os memorialistas na utilização da técnica e leitura dos documentos, as quais identificamos como fonte de informações para satisfazer nossas intenções em descrever os rumos da historicidade da EFSFVS. Optamos em gerar duas categorias representativas que resgatam a historia e ações da Instituição, como veremos a seguir.

A idealização e o surgimento da Escola de Formação em Saúde da Família Visconde de Sabóia

Nesta primeira categoria, nos debruçamos sobre contexto em que a escola surge e a intenção dos seus idealistas. No limiar de uma nova gestão municipal, o setor da saúde de Sobral buscava implementar ações que desenvolvessem nos trabalhadores a tríade ação-reflexão-ação e que, deste processo, resultasse, sobretudo, uma reconstrução de saberes e práticas, visualizando cada trabalhador como um potencializador de transformação.

Diante da conjuntura política de transformações na saúde com adoção de um novo modelo voltado para a comunidade, com fortalecimento da Atenção Básica, Sobral demonstrava um número restrito de profissionais que atuavam na atenção primária, priorizando a atenção secundária e terciária, reflexo de uma cultura há muito implantada.

Era nítida a necessidade de tornar a atenção básica um campo de ação atrativo e que disseminasse a ideia de que muita resolutividade se pode ter a partir deste nível de atenção, considerando-a como "a porta de entrada do SUS". No entanto, havia também a clareza que se tratava de desmistificar um processo cultural e de que as reflexões não poderiam partir do nível central da gestão municipal, mas que pudesse provocar nos trabalhadores uma inquietação acerca de seu desenvolvimento e aprimoramento pessoal e profissional. Tal pensamento está embutido na fala dos sujeitos, como é colocado pelo Coordenador 1:

O objetivo finalístico disso não é simplesmente o médico atuar bem, o enfermeiro atuar bem; é isso refletir nos indicadores da saúde da família, na qualidade de vida da população. Eu acho que isso é o outro papel que ela vem desempenhando ao longo dessa história (C1).

Consciente das necessidades de mudar as práticas decorrentes de um modelo operacional pouco reflexivo, foi identificada a necessidade de deflagrar processos de educação na saúde.

E, neste percurso, a EFSFVS foi se estruturando e galgando espaços para realizar a missão a que se propôs, articulada com um de seus pilares, que é promover processos de educação permanente.

Para provocar processos de subjetivação, a educação permanente na saúde deve implicar os sujeitos com seu próprio processo de trabalho ${ }^{10}$. Diante de tais circunstâncias, foi idealizada uma instituição que somasse com a gestão possibilidades de construir condições para modificar e transformar o modelo de saúde hospitalocêntrico predominante na época. Neste contexto, surge a EFSFVS,

porque a origem da escola, a finalidade da escola era desenvolver mesmo a tal da tecnologia na Estratégia Saúde da Família (C1).

Apresentava-se, desta forma, um ambiente fértil para o deslanchar de uma escola que ansiava qualificação para os trabalhadores, coincidindo com a efetivação da política que estava apenas instituída, carecendo que os demais níveis da administração pública nutrisse o seu desenvolvimento.

Outra memória resgata pela fala dos entrevistados retratando que

[...] o Município aderiu a um projeto muito grande, que era o projeto do [Programa de Apoio às Reformas Sociais do Ceará] PROARES, e, nele, o projeto de construção da Escola de Saúde da Família, inclusive é o prédio que existe até hoje [...] (C2). 
Neste contexto, a EFSFVS vem assumindo juntamente com os municípios as ações mais estruturadas e mais estratégicas para a macrorregião de saúde de Sobral. Porém, de acordo com os sujeitos, ela ainda precisa alavancar em relação a isso e entender melhor no âmbito dos próprios gestores que qualquer trabalhador do SUS pode ser um facilitador de uma ação de educação permanente no seu território.

A educação como instituição atua a partir do humano, isto é, articula sujeitos que trazem como elementos constitutivos do seu ser uma história de vida, uma origem sociocultural, saberes constituídos ao longo da sua formação e vivências no trabalho em saúde. Deste modo, toda a complexidade do viver que forma uma certa subjetividade e coloca em ação nos seus fazeres e pensares, de forma única. Um terceiro pressuposto é o de que, na educação, o trabalho é, em grande medida, relacional e, tal como na saúde, é "trabalho vivo em ato" ${ }^{11}$, tendo os trabalhadores da educação um grande autogoverno do seu processo de trabalho, o que permite disponibilizá-lo por inteiro aos seus "usuários".

Ademais, a EFSFVS vem, também, nesta trajetória, liderando o fomentar de espaços de reflexão das práticas culminando em um acúmulo de experiências exitosas nos processos de Educação Permanente (EP). É inegável a consciência dos sujeitos em reconhecer as incompletudes nas ações. No entanto, é evidente que há uma primazia em cuidar dos processos de forma operante.

Outro resgate memorial obtido foi referente a visibilidade da EFSFVS considerada a primeira do gênero no Brasil, com denominação de Escola de "Saúde da Família" no âmbito nacional, por ter compreendido bem a intencionalidade e os modus operandi de como compreendia a Educação Permanente para o desenvolvimento dos trabalhadores.

\section{Escola de Formação em Saúde da Família Visconde de Sabóia no cenário da educação na saúde no âmbito regional}

Nesta categoria, somaremos as informações colhidas no intento de perceber a EFSFVS no seu cenário de atuação.

Após a VII Conferência de Saúde, a Secretaria de Recursos Humanos do Ministério da Saúde, no sentido de buscar a promoção profissional e intelectual do pessoal de nível médio e elementar, traçou diretrizes gerais visando à formação desses trabalhadores e por entender que os treinamentos em serviços não resolveriam o problema da formação ${ }^{12}$.

E esta necessidade foi sentida pelos gestores da EFSFVS. O objetivo da criação de uma Escola para promover processos formativos, tendo como foco preencher as lacunas da educação permanente para os trabalhadores do SUS do município de Sobral, tomou uma dimensão maior à medida que as ações foram acontecendo e as fragilidades nos serviços foram se evidenciando.

O município de Sobral reconhecendo o papel estratégico da EFSFVS resolveu por meio da Resolução 001/2008 da Secretaria da Saúde e Ação Social de Sobral, assim denominada na época, estabelecer que todos os processos de educação na saúde ficam sob a responsabilidade da coordenação de Educação Permanente da Escola de Formação em Saúde da Família Visconde de Sabóia ${ }^{13}$, como pode ser observado através do resgate memorial do entrevistado B1:

A escola surgiu, acho que ela surgiu muito vocacionada para Sobral, vocacionada para os trabalhadores da saúde da família. Quando ela foi pensada foi muito nisso e como o SUS também foi ficando mais complexo e a própria saúde de Sobral foi se complexificando, a gente vê que a escola ganhou uma dimensão muito grande.

O campo da educação na saúde, apesar de estar em ascensão e, consequentemente, muito fértil, se demonstrava carente no Ceará. Diante disto, a EFSFVS nascia e se desenvolvia com uma expertise bem peculiar de ações no campo formativo.

[...] No primeiro momento, ela tinha esse desenho de ser uma escola municipal, mas depois, né, por conta da inexistência de outras escolas desse caráter na Região naturalmente a equipe da Escola foi tendo uma liderança na Região Norte [...] (C2).

Entretanto, mesmo reconhecida e publicitada como a instituição, na macrorregião de saúde de Sobral, responsável pelos processos formativos, a EFSFVS é uma mobilizadora e incentivadora que os profissionais dos demais municípios da região deflagrem processos de educação permanente, reconhecendo o potencial de cada trabalhador, e não se ausentando da máxima da Educação Permanente que esta acontece "no trabalho, pelo trabalho e para o trabalho":

[...] a gente reconhece que a oferta e quase tudo no setor saúde, se for posto num plano de uma equação ela é insuficiente para as necessidades e demandas, mas também queremos desenvolver, ajudar as microrregiões a se perceberem como potenciais desenvolvedores de ação da Educação Permanente [...] (C3).

O Ministério da Saúde (MS) instituía a PNEPS por meio da Portaria GM 198 de 13 de fevereiro de 2004 com a proposição de transformar e qualificar as práticas de formação, atenção, gestão, controle social/participação popular; a organização dos serviços de saúde e os respectivos processos de trabalho; as práticas pedagógicas de formação e desenvolvimento dos trabalhadores de saúde ${ }^{14}$.

Esta iniciativa do MS norteava as ações de desenvolvimento dos Recursos Humanos intencionando promover processos formativos estruturados a partir da problematização do seu processo de trabalho, cujo objetivo é a transformação das práticas profissionais e da própria organização do trabalho, tomando como referência as necessidades de saúde das pessoas e das populações, da gestão setorial e o controle social em saúde.

A EFSFVS desenvolvia objetivos que antecederam a institucionalização da PNEPS. Trata-se da sua atuação enquanto instituição 
promotora de educação na saúde na macrorregião de saúde de Sobral, compreendendo, aqui, que esta divisão política assume a responsabilidade de cumprir esta ação em um raio de 55 municípios, contemplando as regiões de saúde de Acaraú, Camocim, Cratéus, Sobral e Tianguá. É importante salientar também a vasta dimensão territorial que esta divisão ocupa, muitas vezes carecendo de desenvolver processos descentralizados, o que exige um planejamento e uma execução bastante diferenciada e cuidados especiais.

A participação é condição essencial para a democratização das ações, considerando a relevância e a importância de todos os segmentos na concretização de resultados comuns. Na inspiração Euclidiana, o quadrilátero é um polígono de quatro lados e na concepção da saúde, estes lados são independentes, mas corresponsáveis pela consolidação dos princípios norteadores do SUS.

Nesta próxima categoria, percebemos como a instituição desta pesquisa tem atuado em consonância com as faces do quadrilátero.

\section{A fundamentação das ações da Escola de Formação em Saúde da Família Visconde de Sabóia em concordância com o quadrilátero da formação em saúde}

Incitada com os propósitos da Educação Permanente em produzir sentidos nos sujeitos que promovem e são promovidos pela ideia de formação permanente dos sujeitos que, na sua labuta diária, priorizam o "fazer" saúde. A intenção não é a concentração de fazeres e pensares, mas, sim, uma corresponsabilização e uma acreditação de que todos os sujeitos sejam implicados nesta proposta.

As faces do quadrilátero permitem que a responsabilidade perpasse e permeie o fazer de cada um e, portanto, constituem partes importantes e relevantes no contexto de formação. Esta responsabilidade é lembrada pelos sujeitos no transcorrer desta investigação, na qual tivemos a participação de memorialistas representativos de cada segmento do quadrilátero. Como podemos observar na fala:

[...] a gestão e a participação sempre estavam juntas; isso porque estávamos construindo um processo de gestão participativa, por exemplo, as reuniões tanto do Conselho gestor da Secretaria como o próprio Conselho Municipal de Saúde acontecem na Escola até hoje, então realmente a Escola é um local de catalização e de estimulo esses processos [...] (A1).

Outra evidência identificada pelos documentos analisados foi a de uma intensa relação da EFSFVS com o Controle Social, tais como: as reuniões dessa instância colegiada sempre acontecerem nas instalações da EFSFVS; processos formativos tendo como público-alvo os Conselheiros Municipais de Saúde (CMS) dos municípios da macrorregião Norte do Ceará; participação em conferências e outros eventos protagonizados pelo CMS.

Comungando com os achados nos documentos, o entrevistado C3 retrata a relação entre a instituição e o controle social:
[...] no campo do Município de Sobral, essa atuação é bastante presente que você vai, que a gente vai desde o fortalecimento dos controles locais, dos Conselhos locais de Saúde, então a Escola participou da implantação ativamente nos Bairros, nos Territórios junto a tutoria do Sistema Saúde Escola, dos gerentes ao Conselho Municipal de Saúde articulando diversos segmentos [...] (C3).

A interação entre os segmentos da formação, da atenção, da gestão e do controle social em saúde deveria permitir dignificar as características locais, valorizar as capacidades instaladas; desenvolver as potencialidades existentes em cada realidade; estabelecer a aprendizagem significativa e a efetiva e criativa capacidade de crítica, bem como produzir sentidos, autoanálise e autogestão. Para tanto, teremos de pensar/ providenciar subsídios para que se pense/providencie a Educação Permanente em Saúde ${ }^{15}$.

A interação entre os segmentos construtores de qualquer relação necessita de reflexões para que possa seguir direcionamento em que todos se sintam parte do processo. Assim, segundo os sujeitos, a EFSFVS desde seu nascedouro prima por uma relação de harmonia entre formação, atenção, gestão e controle social, considerando que não há hierarquização na qual um sobreponha o outro, mas posições diferenciadas que em um processo representam determinado segmento e que podem contribuir para o avanço da formação dos trabalhadores da saúde, constituindo, portanto, um cenário de formação polissêmica e corresponsabilizada.

Outro aspecto observado se direcionou ao processo de comunicação entre a EFSFVS e os segmentos integrados que origina o quadrilátero, em pode-se registar através do relatos que:

a gente se comunica e muito. Com o serviço não tem nem como dizer que não porque ela nasceu sobre a lógica de educação permanente. O relacionamento dela com o serviço, a contribuição dela para o serviço, é a razão da existência. Com a gestão também, quando a gente está falando em educação permanente a gente está falando em algo que é um modelo de gestão e com o controle social talvez seja com o que a escola menos interagiu embora tenha interagido muito. A escola nesse tempo de existência ela desenvolveu vários projetos de capacitação também para o controle social, a Escola teve um papel extremamente importante na área da formação, além da escola ser um órgão de formação ela desde o nascimento faz articulação com a UVA, e sempre foi muito intenso (C1).

É de muita clareza que o maior número de processos formativos está concentrado nas áreas da formação e da atenção, mas que ações foram deflagradas para os outros segmentos do quadrilátero, além de que estes percebem a EFSFVS como apoiadora e mobilizadora, tornando-se, assim, protagonistas na realização de ações em saúde.

A gênese da EFSFVS credencia como uma instituição inerente ao SUS. O público-alvo, os objetivos, as metodologias, o modelo 
pedagógico, a epistemologia, as conquistas, o referencial teórico, o cenário, tudo converge para personalizá-la como uma escola do sistema de saúde adotado no Brasil. Ancorada pelo modelo das escolas técnicas do SUS, busca identificar estratégias de ensino para aperfeiçoar o processo de formação dos profissionais de saúde, estimular a educação permanente dos profissionais dos serviços e do processo contínuo de melhoria de qualidade de vida dos usuários, em uma perspectiva de formar no SUS, para o SUS e pelo SUS.

De acordo com o que foi enfatizado por alguns dos protagonistas deste estudo, a EFSFVS teve sua criação e implantação a partir da necessidade de formação e educação permanente para os trabalhadores. No entanto, no âmbito da saúde, registrava-se que o déficit de pessoal devidamente qualificado se estendia igualmente a outras áreas, consistindo em um grande desafio a ser superado.
Ainda no contexto, outra influência que concorreu para o estabelecimento da escola foi a institucionalização de Políticas Públicas no seio da Reforma Sanitária, uma vez que necessidades de mudanças nos serviços foram visualizadas, enfatizando a necessidade de formação/qualificação profissional.

Acredita-se que este estudo tem sua relevância e os propósitos atendidos, haja vista que foram ressaltados por todos os sujeitos convidados a importância e o reconhecimento pela iniciativa e interesse no assunto, por se tratar de uma produção inédita, e o desenvolvimento de publicações sobre esse tema tem sido muito ínfimo, ainda diante das possibilidades que este pode desencadear, tornando-se atrativo e potencial referência para outros trabalhos que venham a ser objeto semelhante. Todavia, poderá constituir ainda peça de acervo bibliográfico nos equipamentos de estudos, subsidiando avaliações por parte dos gestores e possibilitar argumentos para a efetivação de ações e intensificação das ações da PNEPS a nível macrorregional.

\section{REFERÊNCIAS}

1. Ponte CF, Falleiros I. Na corda bamba de sombrinha: a saúde no fio da história. Rio de Janeiro: Fiocruz; 2010; p.340.

2. Brasil. Constituição da República Federativa do Brasil. Constituição (1988): promulgada em 5 de outubro de 1988. Disponível em: http://bvsms.saude.gov.br/html/pt/legislacao/ constituicao_196_200.html. Acesso em: 05 fev. 2013.

3. Oliveira GHC. Oportunidade perdidas: uma comparação entre os anos Collor e o Primeiro Governo Lula. Monografia (Trabalho de Conclusão de Curso) - Universidade Estadual de Campinas. Campinas: 2008 .

4. Galvão E. Cenário Nacional das Escolas Técnicas do SUS: a criação dos CEFOR no Brasil. Saúde Soc. 2009:18(supl.2):60-3. http://dx.doi.org/10.1590/S0104-12902009000600009

5. Queiroz MI. Relatos orais: do indizível ao dizível. In: Von Simon OM. Experimentos com história oral. São Paulo: Vértice, 1988.

6. Meihy JCSB. Manual de história oral. 4. ed. São Paulo: Loyola, 2002.

7. Minayo MCS. O desafio do conhecimento: pesquisa qualitativa em saúde. 7. ed. São Paulo: Hucitec; 2010; 269 p.

8. Prefeitura Municipal de Sobral. Secretaria da Gestão. Decreto $n^{\circ} 1.247$, de 13 de agosto de 2010. Cria a Escola de Formação em Saúde da Família Visconde de Sabóia. Impresso Oficial do Município Sobral. Disponível em: http://www.sobral.ce.gov.br/ iom/486.pdf. Acesso em: 14 mar. 2013.
9. Brasil. Ministério da Saúde. Conselho Nacional de Saúde. Resolução $n^{\circ} 466$ de 12 de dezembro de 2012. Aprovar as seguintes diretrizes e normas regulamentadoras de pesquisas envolvendo seres humanos. Diário Oficial da União. Brasília: Ministério da Saúde; 2012.

10. Merhy EE. O desafio que a educação permanente tem em si: a pedagogia da implicação. Interface. 2005;9(16):172-4 http://dx.doi.org/10.1590/S1414-32832005000100015

11. Merhy EE. Em busca do tempo perdido. In: Merhy EE, Onocko R Agir em saúde: um desafio para o público. São Paulo: Hucitec 1997; p. 71-112.

12. Pereira IB, Ramos MN. Educação profissional em saúde. Rio de Janeiro: Fiocruz; 2006; p.120.

13. Prefeitura Municipal de Sobral. Secretaria da Saúde e Ação Social de Sobral. Resolução n 001, de 15 de fevereiro de 2008 Estabelece que todos os Processos de Educação Permanente ficam sob a Responsabilidade da Coordenação de Educação Permanente. Escola de Formação em Saúde da Família Visconde de Sabóia. Impresso Oficial do Município. Sobral. Disponível em: http://www.sobral.ce.gov.br/iom/222.pdf. Acesso em: 14 mar. 2013.

14. Brasil. Ministério da Saúde. Secretaria de Gestão do Trabalho e da Educação na Saúde. Departamento de Gestão da Educação na Saúde. Portaria GM/MS n 198, de fevereiro de 2004. Institui a Política Nacional de Educação Permanente em Saúde. Brasília: 2004.

15. Ceccim RB. Educação Permanente em Saúde: desafio ambicioso e necessário. Interface. 2005:9(16):161-77. 